\title{
Economic spill-over of food quality schemes on their territory
}

\begin{abstract}
We study the effect of a set of food quality scheme (FQS) products within the local economy using a local multiplier approach based on LM3 methodology. To evaluate the effective contribution within the local area we compare each FQS product with its equivalent standard/conventional counterpart. Local multiplier allows us to track the financial flows converging within the local area at the different levels of the supply chain so that we can measure the FQS product role in local economic activation. Overall, the FQS products exhibit a higher positive contribution to the local economy than the standard references. However, there is significant heterogeneity in the impact according to the product categories. In the case of vegetal products, the local economic advantage due to FQS is $7 \%$ higher than the reference products, but the statistical tests reject the null hypothesis that the medians are significantly different from zero. On the contrary, animal products exhibit a larger contribution of FQS than the standard counterparts (+24\%). The PGI products (+25\%) produce the major effect, while PDO products show a median difference lower $(+6 \%)$. The organic and non-organic products seem to be substantially equivalent in terms of contribution to the local economy, due to the similarity in the downstream processing phase.
\end{abstract}

Keywords: Local multiplier, Food quality scheme, Economic spill-over, Local areas, Rural development

JEL code: Q12, Q18, E12, F61 


\section{Economic spill-over of food quality schemes on their territory}

\section{Introduction}

EU recognizes to food quality scheme (FQS) products (i.e. organic, PDO, PGI, and TSG products) the role of promoting socio-economic development in rural areas with the aim of keeping the viability in such areas (European Commission, 2017). This is one of the main objectives of the EU's quality food policy together with the production of public goods, such as the typical rural landscape, peasant heritage, and rural community texture. The strong linkage of the FQS products with the corresponding geographical areas of origin ensures a contribution to the local economic growth and local employment (Raimondi et al., 2018; Tregear et al., 2007). Although not mutually exclusive, FQS products generally belong to the local food supply chain, where the food supply can follow two main models of development: "local to local" and "local to global" (Mancini and Arfini, 2018; Morris and Buller, 2003).

The "local to local" model entails "innovative" food supply channels including farmers' markets, farm shops, roadside sales, pick-your-own operations, box schemes, home deliveries, mail order, and e-commerce (Renting et al., 2003). The advocates of the "local to local" model refers to it as Short Food Supply Chain (SFSC) for emphasizing a very close relationship between producer and consumer. SFSC knows an increasing diffusion in rural areas and establishes an innovative way to face the food market by a direct linkage with consumers that means selling food products with a composite set of local values, i.e. traditional methods of productions and sales, countryside lifestyle, firm reputation, rural community, and territorial protection. Since the supply chain is shortened, the proportion of value-added captured by farmers is higher than in the long frame (Morris and Buller, 2003). For all the previous reasons, SFSC is also identified as a tool for fostering rural development (Marsden et al., 2000).

According to the "local to global" approach, local production and worldwide marketplace characterize quality food products. In other terms, the food product is not just sold within the origin area but it is also addressed to domestic and export markets. Some examples of those FQS products comprise Parmigiano-Reggiano in Italy, Roquefort in France, and Feta in Greece. Mancini and Arfini (2018) classify this approach as a mixed localized agri-food system (LAFS), where local companies benefit from connections with local and non-local actors contributing to shaping a stable network of stakeholders along the supply chain with positive impacts on local and rural development (Tregear et al., 2007).

Although the above categorization can be mainly referred to PDO, PGI, TSG products, it can be recognized a perceived close relationship between organic and local food products (Lobley et al., 2009). Organic produce is not necessary "local" (it is quite evident in the case of the organic products supplied in supermarkets), but when locally produced it represents a powerful tool for developing the local economy (Renting et al., 2003; van der Ploeg et al., 2018) by retaining a large part of the farming and food expenditure within the local area (Smithers et al., 2008). Despite the potential role organic food products can play within the local area, the connection with the local economy relies on farm type, farming system, marketing strategy (Lobley et al., 2009), supply chain structure, and interactions with local actors (Marasteanu and Jaenicke, 2018).

Beyond the relevant social and environmental effects, the contribution to the local economy and development appears as a key variable for evaluating the level of sustainability of the FQS products. Evaluating the economic impact at local level of the FQS products requires however an adequate methodology able to capture in a clear and reliable manner how the food supply chain can affect the local economy growth.

This paper aims to assess the contribution of a set of FQS products to the local economy trying to capture the contribution of the different actors along the food supply chain. For this purpose, scientific literature offers a wide range of approaches which can be classified into three main categories: 1) economic connectivity or spatial distribution analysis; 2 ) input-output models; 3 ) economic multipliers. 
The spatial distribution analysis of economic units can be considered among the first attempts to relates agrifood activity to local economies. In the seminal research work of Harrison (1993), economic transactions of a small sample of UK farms are identified through the postcodes of farm invoices (purchases and sales), so that author could classify each supplier and customer as rural or urban and, thus, evaluate the monetary retention and leakage in rural areas. Based on this methodology, Lobley et al. (2009) investigated the economic connectivity of organic and non-organic farms. The results demonstrated that at aggregated level, the economic connectivity is not very dissimilar between the two typologies of farms, but by combining organic status with farm type authors identified those organic farms exhibiting a strong local economic connection. Authors argue that treating organic and non-organic farms as homogenous sectors is too simplistic because the local (production) specificities affect rural development potential. More recently, Pangbourne and Roberts (2015) turn on Harrison's methodology proposing an analysis of the spatial pattern of upstream and downstream agricultural transactions of 224 farms in North East Scotland. One of the main findings of their study showed that the spatial concentration of the upstream and downstream agribusinesses represents a determinant of local economic interaction. This is the case of fertilizers, for which most of the farms bypass local suppliers purchasing their fertilizers in reference distant markets, where the source of farm inputs is concentrated. Harrison's methodology and its extensions detect direct economic and territorial linkages while neglecting indirect and induced effects on the local economy (Pangbourne and Roberts, 2015). The methodology allows an appraisal of the farm's commercial flows, upstream and downstream, but the injection of spending at local level by farm providers is not determined, i.e. the approach focuses on the first round of transactions in the economy (Courtney and Errington, 2000). Furthermore, the rate of spending within the local area due to non-local businesses is neglected and the offfarm expenditure (e.g. family and workers spending) is not directly recoverable as well.

It is clear that the economic activity of local actors (firms and households) interweaves with the rest of the economy in a continuum of interactions whose effect is reflected in the local economy dynamic. This more comprehensive picture of the economic processes is achievable using the input-output approach (Leontief, 1974). The idea that multiplier effects exist when a certain level of output needs inputs is embedded in a wide spectrum of economic analysis mainly applied at regional level (Robison, 1997; Wiedmann, 2009). Johns and Leat (1987) proposed a regional input-output model for the Grampian region in North-East Scotland whose follow-up research is due to Roberts (1998) dealing with the nature of ex-post interdependencies between town and countryside through a social accounting matrix (SAM) approach. Her research points out the need to study interdependencies in rural economies beyond the output-related linkages, which calls for an extension of the partial analysis of production-based input-output tables. There is therefore a relationship between input-output tables and SAM to the extent that SAM can show the entire circular flow of income at meso-level (Stahmer, 2004). The use of SAM approach was particularly applied to the analysis of the urbanrural linkages and their effect on rural development (Balamou and Psaltopoulos, 2006; Courtney et al., 2007; Hyytiä, 2014; Pieters, 2010; Psaltopoulos et al., 2006; Roberts, 1998). This approach is generally applied at macro- and meso-level rather than at local level because of the availability of data at lower territorial scale. SAMs are very demanding in terms of data (Round, 2003) and constrained by several assumptions, such as the fixed technology and prices. This means that technological and structural change and market fluctuations cannot be easily embedded in such models.

Tracking the spending within the local area comprising the different levels of a given supply chain may address the need to estimate total monetary flow participating in the local economy viability. In 2002, the New Economic Foundation (NEF) developed a Keynesian-based multiplier called LM3, which stands for "Local Multiplier 3", with the aim to provide governments, businesses and organizations, communities, and individuals with a tool to estimate their role in fostering local economy (Sacks, 2002). The calculation procedure articulates into three rounds: 1 ) determining the budget of the organisation for which we are seeking the extent of its contribution to the local economy; 2 ) identifying the amount of expenditure of the organization for its local and non-local suppliers (e.g. staff, contractors and sub-contractors, suppliers of good and services, investments, financial services, etc.); 3) assessing the share of money identified in round 2 respent within the local area. The three rounds computation results in an indicator of the financial flow activated by 1 euro of initial budget within the local economy, calculated as a ratio of the total expenditure 
within the local area including initial budget (round $1+$ round $2+$ round 3 ) to initial budget (round 1 ). The higher the indicator, the higher the positive effect of an organisation within the local area. More income retained at local level corresponds to more local employment, more benefits for local governments and, finally, better well-being for the local population (Bengo et al., 2016; Sacks, 2002). The main difference with the Harrison approach is that the location of the buyer (sales) is not considered and that the purchases of suppliers are considered. In our study, we adopt a methodology that extends LM3 to FQS products. LM3 approach was mainly applied in the UK context (Burke and King, 2015; Courtney et al., 2013; Dowler et al., 2003; McDonald and Boden, 2012; Mitchell, 2017; Mitchell and Lemon, 2019; Potts, 2008; Slee, 2006; Thatcher and Sharp, 2008), although some applications in other countries exist (Březina and Hlaváčková, 2016). In contrast to the spatial analysis, LM3 comprises in the spatial patterns the value of transactions, which is retrieved with a survey of the actors participating in the supply chain; furthermore, LM3 captures indirect transactions along the chain. Despite SAMs, LM3 models cannot depict in a comprehensive way the numerous interactions as well as the flows of income in an economy (Courtney et al., 2013). However, LM3 benefits from several simplifications, such as a less reliance on secondary data than SAMs and a more delimited system boundaries (i.e. 3 spending rounds), that makes LM3 principles and results more comprehensible to local stakeholders (Courtney et al., 2013; Slee, 2006). Therefore, the relatively simpler implementation of LM3 permits to analyse the economic spill-over in local communities without sustaining the high costs of a complex modelling approach.

The assessment of the contribution of FQS products to the local economy proposed in this paper is carried out through the implementation of an LM3-derived indicator. This is the first attempt to extend the LM3 approach to the evaluation of organic, PDO, and PGI products. The study compares local multipliers for 15, animal and vegetal origin, FQS products with the corresponding standard (or conventional) equivalent ones. The methodology was developed in the framework of the Horizon 2020 project "Strenght2Food" ${ }^{1}$.

The paper is organized as follows: Section 2 reports the methodological extension of LM3 to the FQS products and the data collection strategy; Sections 3 and 4 show and discuss the results; Section 5 concludes and presents the main policy implications of the work.

\section{Material and Methods}

\subsection{Local multiplier for FQS products}

LM3 was originally developed by the New Economics Foundation as a way to demonstrate the benefit of local organisations to their communities. In this study, the local multiplier indicator originates from the LM3 approach and provides a measure of the impact of the FQS product and its equivalent standard product (the "reference") on the local economy. A thumbnail sketch of the entire procedure of the local multiplier for the FQS product and its reference may be more meaningful.

Figure 1 depicts the phases and actors involved in the evaluation procedure. Initially, the total turnover of the downstream firm in the supply chain, where most part of the product value concentrates, is recovered. For instance, in the case of FQS cheese (e.g. Parmigiano-Reggiano, Comté), the downstream firm corresponds to dairies. The identification of the downstream firm entails some assumptions about the system boundary of each FQS product because it is quite unlikely to trace the entire flow of money along the entire supply chain (Mitchell and Lemon, 2019).

Generally, round 1's firm corresponds to the first processor (e.g. dairies). Therefore, the amount of money in the first round comprises the share of expenditure retained in the local economy and determined in the following rounds:

$$
R_{1}=b
$$

Where $R_{1}$ is the amount of budget $b$ of the target downstream actor in the supply chain.

\footnotetext{
${ }^{1}$ https://www.strength2food.eu/
} 
Figure 1. Phases of local multiplier computation for FQS products

Round 1

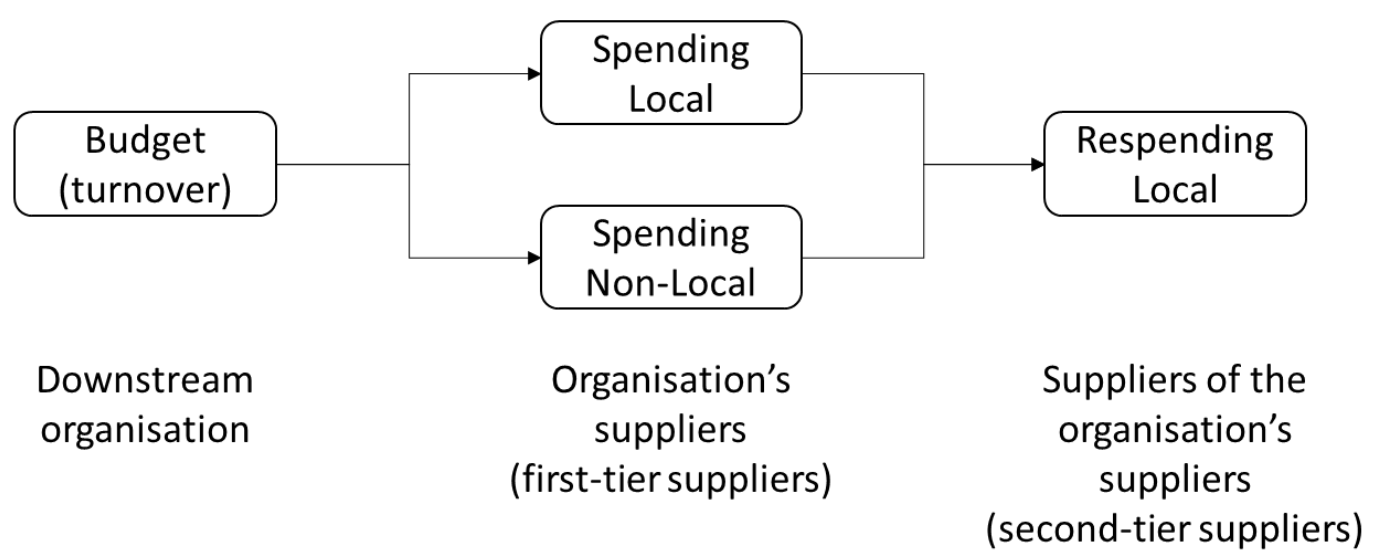

An in-depth analysis of the upstream suppliers is needed for the second round. It is clear that the number and type of first-tier suppliers depend on the technical and territorial specificities of the FQS products and supply chain, but typically they comprise staff, raw material suppliers, energy suppliers, transportation service providers, financial service and capital suppliers, and public administration. In Round 2, the share of budget addressed to local and non-local suppliers is detected. The criteria used to discriminate local from non-local actors is the place where they take the main strategies and decisions. More specifically, if for staff people the local spending is defined according to the residence place, for companies we referred to the headquarter location. Taking up the FQS cheese example, the share of budget paid to dairy farms for the supplied raw milk is accounted into Round 2 by distinguishing the money transfer to local farms from the non-local ones. The result of Round 2 is the amount of initial budget (turnover) spent within a defined area. Formally, the local spending in round 2 is calculated according to the following formula:

$$
R_{2}=\sum_{i=1}^{I}\left(b \cdot \sigma_{i j}\right) \text { for } j=1
$$

where $R_{2}$ identifies the local spending in the second round; while $b$ is the budget identified in the first round and $\sigma_{i j}$ represents the share of budget attributed to each first-tier supplier $i$ (for $i=1, \ldots, I$ ) within the area $j$ (for $j=1,2$ ); $j$ is equal to 1 when suppliers are located within the local area and 2 otherwise. As stated by equation (2), in the second round, we calculate the total budget retained within the local area at first-tier supplier level.

The income stream originating from the actors in Round 2 is the focus of Round 3.

Round 3 aims at gathering information on the first tier suppliers spending within the local area. In the cheese supply chain, farms (first-tier suppliers) hire workers and pay for seeds, fertilizers, fuel, and other inputs from local and non-local businesses (second-tier suppliers). The total local spending in round 3 is calculated according to the following equation:

$$
R_{3}=\sum_{k=1}^{K} \sum_{j=1}^{2}\left(R_{2} \cdot \alpha_{k j}\right)
$$

where $R_{3}$ is the local spending in the third round; $\alpha_{k j}$ is the share of local spending of $R_{2}$ linked to each second-tier supplier $k(k=1, \ldots, K)$ located within or outside the local area.

It is not infrequent that missing data occur at this stage, because of lacking responses from surveyed suppliers and unavailability to provide sensitive information (Mitchell and Lemon, 2019). The distribution of the staff's income into the different consumption baskets is an example of sensitive information not easy to obtain. To address this issue, missing data has been fulfilled following a three-level approach: first, we solicited data 
collectors to interview supply chain experts (scholars and professionals); without data from the previous level, we calculated average values of closer FQS products in terms of geographical distribution and product type; third, for workers and investors' income distribution, we referred to the LM3-related default values provided by New Economic Foundation (Sacks, 2002) ${ }^{2}$. As other authors argued (Mitchell and Lemon, 2019; Thatcher and Sharp, 2008), the evidence of this study pointed out that the main limitation of LM3 concentrates in Round 3, because of the difficulty to get complete and reliable primary data on first-tier supplier re-spending.

The local multiplier indicator calculated in this study is, thus, obtained as a ratio of the total sum of the value resulting from the equations (1)-(3) to the budget of the target downstream actor:

$$
L M=\frac{R_{1}+R_{2}+R_{3}}{R_{1}}
$$

LM returns the spill-over effect of one euro spent in the downstream supply chain within the local economy and it ranges between 1 (i.e. no local economic effects) and 3 (i.e. the budget is entirely retained within the local area along the three rounds). LM is a "global" local multiplier indicator because it accounts for the entire value generated in the three rounds by local and non-local suppliers. By isolating the contribution of local suppliers, it is possible to calculate the local multiplier as if all the budget was spent for local suppliers; a similar indicator can be calculated for the contribution of non-local suppliers only.

\subsection{FQS products and data collection strategy}

We computed the local multiplier indicator for 15 FQS products, as reported by the list in Table 1, of which 7 vegetal-based and 8 animal-based produces. For the sake of simplicity, also organic salmon is included in the category of animal productions. The FQS products selection mainly relies on the strategy developed in the framework of the Strength2Food project aiming at covering representative FQS products for each participating country (Barczak et al., 2016). 4 products are organic, 8 PGI and 3 PDO; 5 products originate from non-EU countries ${ }^{3}$.

Data along the tree rounds was collected through a data grid delivered to each case study conductor with the list of variables necessary for calculating the local multiplier. In particular, variables distinguish between "key" and "complementary" variables. The former type of variables was crucial for the indicator computation, while the latter was optional because it refers to adding elements providing details to the key information. For the complete list of variables adopted in this study, see Appendix.

To simplify data collection and processing, the spending was divided into three categories: payroll, core inputs spending, and non-core inputs spending. Payroll refers to the wages paid by the downstream economic unit in Round 1; core input is the main raw material entering in the technical and economic processing of the economic unit in Round 1; finally, non-core inputs relate to all those goods and services different from core-input and used by the economic entity in Round 1, such as transportation services, packaging material, energy provision, and bank service.

\footnotetext{
${ }^{2}$ Original LM3 procedure identifies values for Round 3 through the data collected by LM3online.com across all of the various LM3 projects where NEF is involved.

${ }^{3}$ Regulation (EC) No. 510/2006 on PDOs and PGIs and No. 509/2006 on TSGs allow third country producers to access the system of protection of geographical indications, as requested by the World Trade Organisation (WTO). Organic products from non-EU countries can be recognized in EU only if they meet the equivalent standards as European produced goods.
} 
Table 1. List of FQS products

\begin{tabular}{|c|c|c|c|c|c|}
\hline Product & Country & Type of food & $\begin{array}{l}\text { Animal/ } \\
\text { Vegetal }\end{array}$ & FQS & $\begin{array}{l}\text { Case study conductor/ } \\
\text { Data collector }\end{array}$ \\
\hline $\begin{array}{l}\text { Organic } \\
\text { tomato }\end{array}$ & Italy & $\begin{array}{l}\text { Processed } \\
\text { Tomatoes }\end{array}$ & Vegetal & Organic & University of Parma \\
\hline Camargue Rice & France & Rice & Vegetal & Organic & $\begin{array}{l}\text { Ecozept - Sustainable development for } \\
\text { agriculture and food sectors }\end{array}$ \\
\hline $\begin{array}{l}\text { Thung Kula } \\
\text { Rong-Hai } \\
\text { Hom Mali rice }\end{array}$ & Thailand & Rice & Vegetal & PGI & Kasetsart University \\
\hline Zagora apples & Greece & Apples & Vegetal & PDO & $\begin{array}{l}\text { Aristotle University of } \\
\text { Thessaloniki }\end{array}$ \\
\hline $\begin{array}{l}\text { Buon Ma } \\
\text { Thuot coffee }\end{array}$ & Vietnam & Coffee & Vegetal & PGI & $\begin{array}{l}\text { University of Ho Chi Minh } \\
\text { City }\end{array}$ \\
\hline $\begin{array}{l}\text { Doi Chaang } \\
\text { coffee }\end{array}$ & Thailand & Coffee & Vegetal & PGI & Kasetsart University \\
\hline Organic flour & France & Wheat flour & Vegetal & Organic & $\begin{array}{l}\text { Institut National de Recherche pour } \\
\text { I'Agriculture, l'Alimentation et } \\
\text { I'Environnement (INRAE), Dijon }\end{array}$ \\
\hline Comté & France & Cheese & Animal & PDO & $\begin{array}{l}\text { Institut National de Recherche pour } \\
\text { I'Agriculture, l'Alimentation et } \\
\text { I'Environnement (INRAE), Dijon }\end{array}$ \\
\hline $\begin{array}{l}\text { Parmigiano- } \\
\text { Reggiano }\end{array}$ & Italy & Cheese & Animal & PDO & University of Parma \\
\hline Sjenica cheese & Serbia & Cheese & Animal & PGI & University of Belgrade \\
\hline Gyulai sausage & Hungary & $\begin{array}{l}\text { Processed pork } \\
\text { meet }\end{array}$ & Animal & PGI & $\begin{array}{l}\text { Eco-Sensus Kozhasznu - Research and } \\
\text { Communication Nonprofit Ltd. }\end{array}$ \\
\hline $\begin{array}{l}\text { Sobrasada de } \\
\text { Mallorca }\end{array}$ & Spain & $\begin{array}{l}\text { Processed pork } \\
\text { meat }\end{array}$ & Animal & PGI & $\begin{array}{l}\text { Center for Agro-Food Economics } \\
\text { and Development (CREDA), Barcelona }\end{array}$ \\
\hline $\begin{array}{l}\text { Ternasco de } \\
\text { Aragon }\end{array}$ & Spain & $\begin{array}{l}\text { Processed } \\
\text { sheep } \\
\text { meat }\end{array}$ & Animal & PGI & $\begin{array}{l}\text { Center for Agro-Food Economics } \\
\text { and Development (CREDA), Barcelona }\end{array}$ \\
\hline $\begin{array}{l}\text { Dalmatian } \\
\text { Prosciutto }\end{array}$ & Croatia & $\begin{array}{l}\text { Processed pork } \\
\text { meet }\end{array}$ & Animal & PGI & University of Zagreb \\
\hline $\begin{array}{l}\text { Organic } \\
\text { Salmon }\end{array}$ & Norway & Smoked Fish & Animal & Organic & $\begin{array}{l}\text { Oslo and Akershus University College of } \\
\text { Applied Sciences }\end{array}$ \\
\hline
\end{tabular}

The downstream target economic entity for round 1 was the producer or processor/manufacturer whose output is the final product in nature before being sold to the wholesaler (e.g., ripened cheese rather than milk, flour rather than wheat). This approach entails that it is likely that only one or two firms/farms of the chain will need considering to generate sufficient data to feed the calculation procedure. Because many producers will be part of the processors' supply chain, the wider socio-economic impacts will be picked up by this method. The decision about the downstream entity and, consequently, the relative supply chain, has been led by the criteria of representativeness of the typology of actors involved in the FQS supply chain (i.e., small, medium, or large enterprises/farms; plain, hill or mountain areas) (Bellassen et al., 2016) ${ }^{4}$.

\footnotetext{
${ }^{4}$ The detailed procedure of data collection is described in Section "Indicator Index Card nEc2: LM3 (Economic Impact)" of the Deliverable 3.2 "Methods and Indicators for Measuring the Social, Environmental and Economic Impacts of Food Quality Schemes, Short Food Supply Chains and Varying Public Sector Food Procurement Policies on Agri-Food Chain Participants and Rural Territories", https://www.strength2food.eu/2016/10/03/methodological-handbook/
} 


\subsection{Definition of the Local Area}

For this type of analysis, a key methodological issue is how to define the local area for different supply chains and FQS products. The localness for FQS products depends on the structure of the supply chain, including the network of stakeholders, and for the geographical indications also on the code of practice. Some approaches identify as local all the transactions falling within an arbitrary radius from the location of the holding (Lobley et al., 2009), when transactions occur within the distance of the nearest town to the holding (USDA, 2008), or according to the distance of the nearest input market (Pangbourne and Roberts, 2015). In LM3-based studies, the definition of "local" is associated with the geographical boundaries of the case study (Thatcher and Sharp, 2008), with an area described by a radius from a specific location (Mitchell and Lemon, 2019) or in terms of accessibility to urban areas (Courtney et al., 2013).

In this study, the general guidelines provided to case study conductors identified the local area for geographical indications (PDO, PGI, TSG) as the area included in the code of practice specification of each FQS product. In the case of organic products, the local area was defined as the NUTS2 region surrounding where the firm is located or a circle of $50 \mathrm{~km}$ radius around the processor considered in round 1 . If administrative boundaries are easier for the case study conductor to use, then the relevant administrative area summing up to around the same surface could be used instead. Beyond the previous general guidelines, for the local multiplier scope, it was important to give evidence of the criteria employed to define the Local Area. For instance, in the case of organic salmon, we selected as local area the main farming and producing district of Norway (i.e. Møre og Romsdal and Senja regions) by covering an area with a radius of $70 \mathrm{~km}$ from the centre of this district (i.e. Andalsnes city).

\section{Results}

In what follows, we present the main results of the local multiplier assessment of the FQS products. Whenever relevant, a comparison with reference products will be proposed. In particular, for evaluating the different contributions to the local economy between FQS and reference supply chains, some statistical evidence will be provided.

\subsection{Vegetal sector}

The analysis of the financial flows along the three rounds shows that almost all vegetal products exceed a local multiplier value of 2 (Figure 2). This means that 1 euro spent within the value chain generates one more euro for the local economy. In particular, FQS products exhibit a better contribution than the reference products, except for organic flour. Organic flour differs from the other products both in the absolute level of local multiplier and in comparison with its reference. This is due to the fact that the volume of local organic grain is not sufficient to satisfy the milling industry demand so that a significant part of the raw material originates from outside the NUTS2 region of the mill.

On average, both FQS and the reference products show local multiplier values higher than 2 . This is an interesting finding, since the reference products selected as the counterpart of the corresponding FQS product are all beneficial for the local economy and their local contribution is not very different from the FQS. The average discrepancy between FQS and reference products is slightly higher than $2 \%$ and the median discrepancy is around 7\%, although some more relevant inner differences exist, as in the case of Carmargue rice, Buon Ma Thuot Coffe, and French Organic flour (Figure 3). The median local multiplier confirms the fact that FQS and reference have a similar impact at local level: for both the products the median is 2.3 ( 1 euro spend triggers a financial flow of 2.3 euro in the local economy). Indeed, despite the focus of many geographical indications on the local sourcing of the raw material, local sourcing largely happens for the reference product as well: transporting raw food products is costly due to their low density (Kilkenny, 1998) and processing plants accordingly source their raw materials from their neighbourhood to the extent possible (Bellassen et al., submitted). Hence, the difference is small, but consistently in favour of FQS except for organic flour (Figure 3). 
Figure 2. Local multiplier indicator for FQS and reference (REF) products - Vegetal sector

3

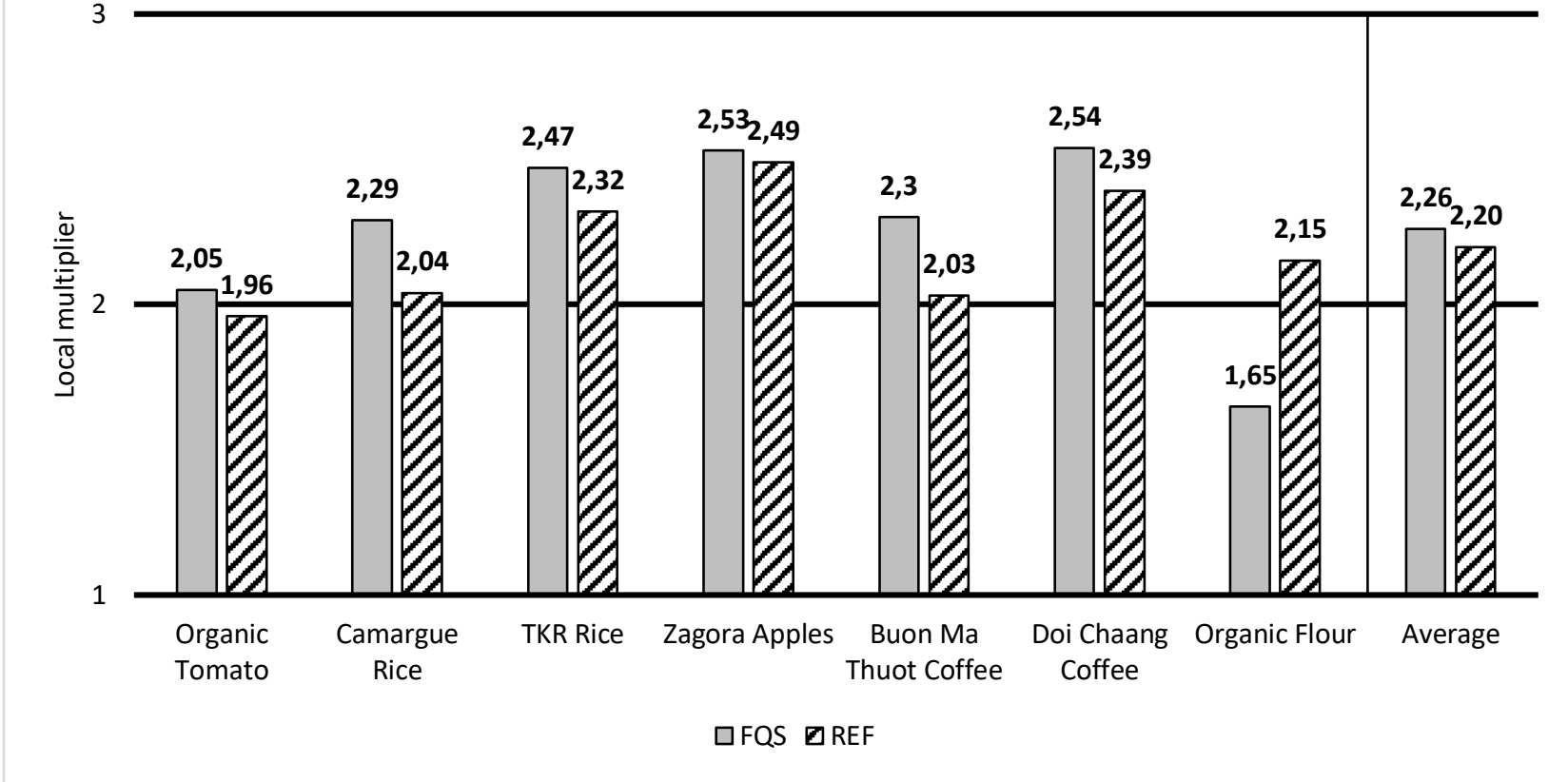

The analysis of the local multiplier composition shows that the local financial flows along the supply chain rounds are substantially evenly distributed between first- and second-tier suppliers. Figure 4 demonstrates this finding, where third round (second-tier suppliers) loose part of the financial flow produced by the second round. This financial leakage effect is due mostly to the non-core inputs from second-tier suppliers, less committed in the supply chain than the core input suppliers; in any case, their contribution is not negligible, although slightly lower than the first-tier suppliers.

Figure 3. FQS variations in local multiplier with respect to the reference - Vegetal sector

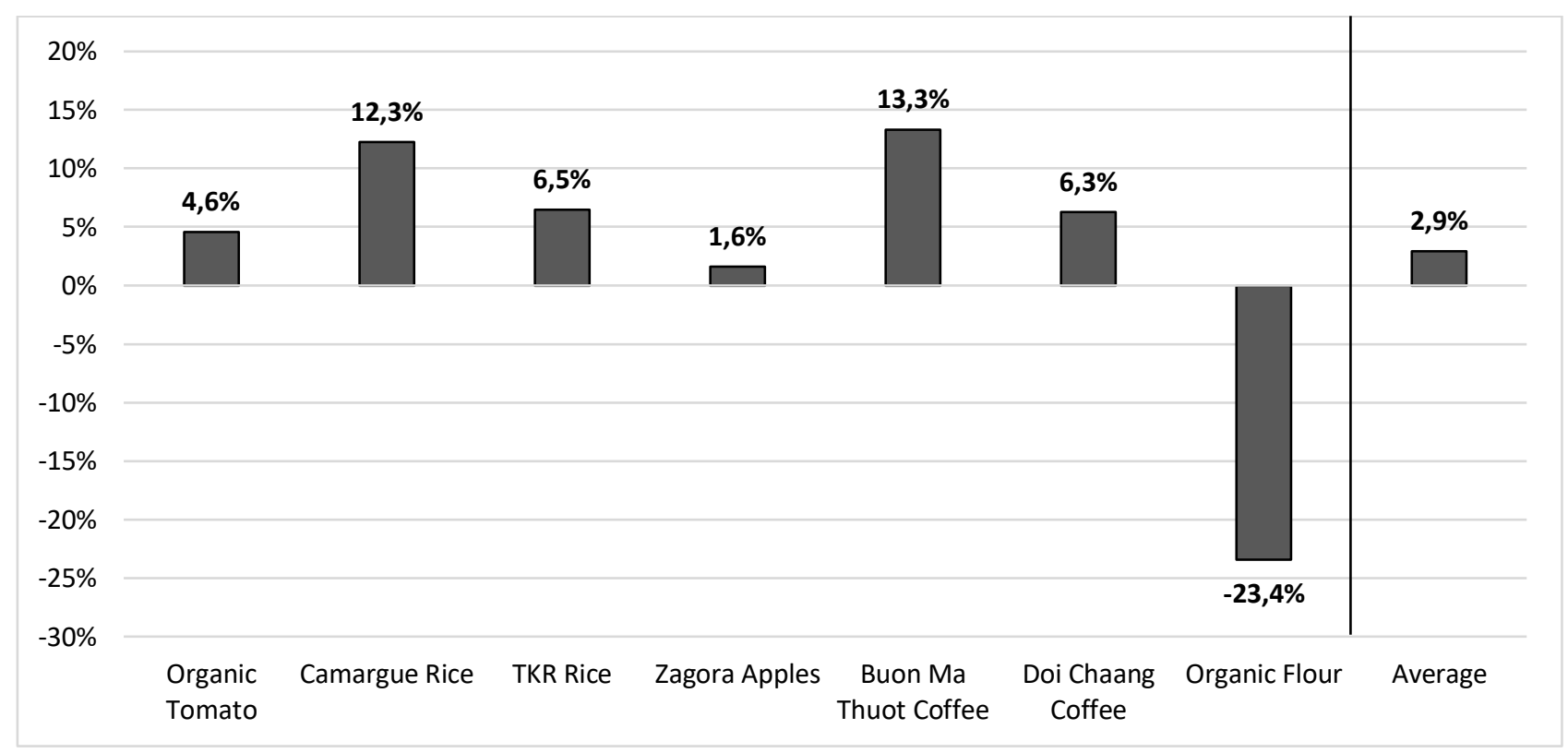


Figure 4. Round composition - Vegetal sector

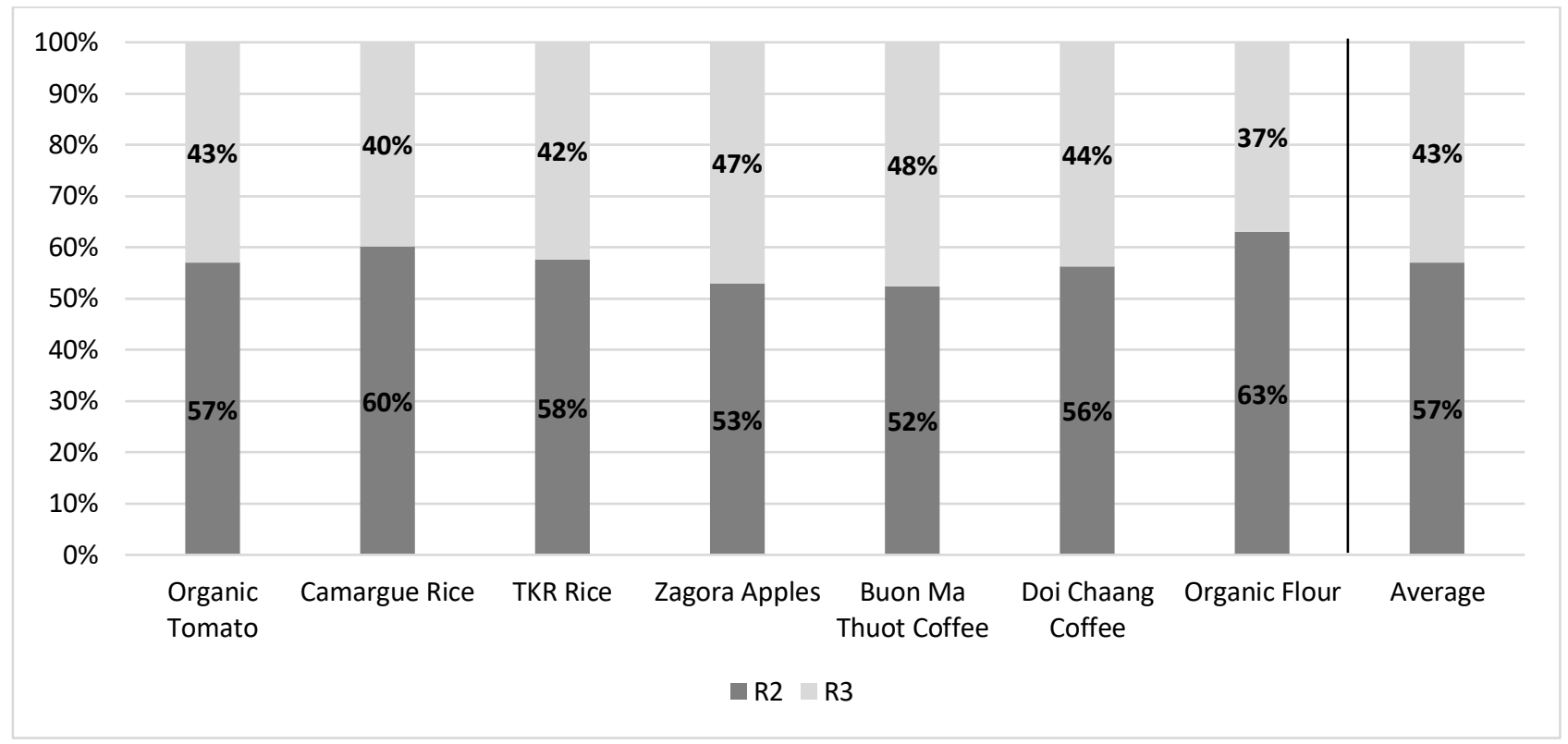

For identifying the risk of deterioration of the local multiplier of the vegetal products, we assumed the disappearance of local suppliers within the value chain for each FQS products. More specifically, we simulated that the current system shifts towards a setting with only non-local actors so that we can measure the impact of this extreme scenario on the current LM and the extent of which each phase of the supply chain might affect the current LM.

Figure 5. Local multiplier determinants - Vegetal sector

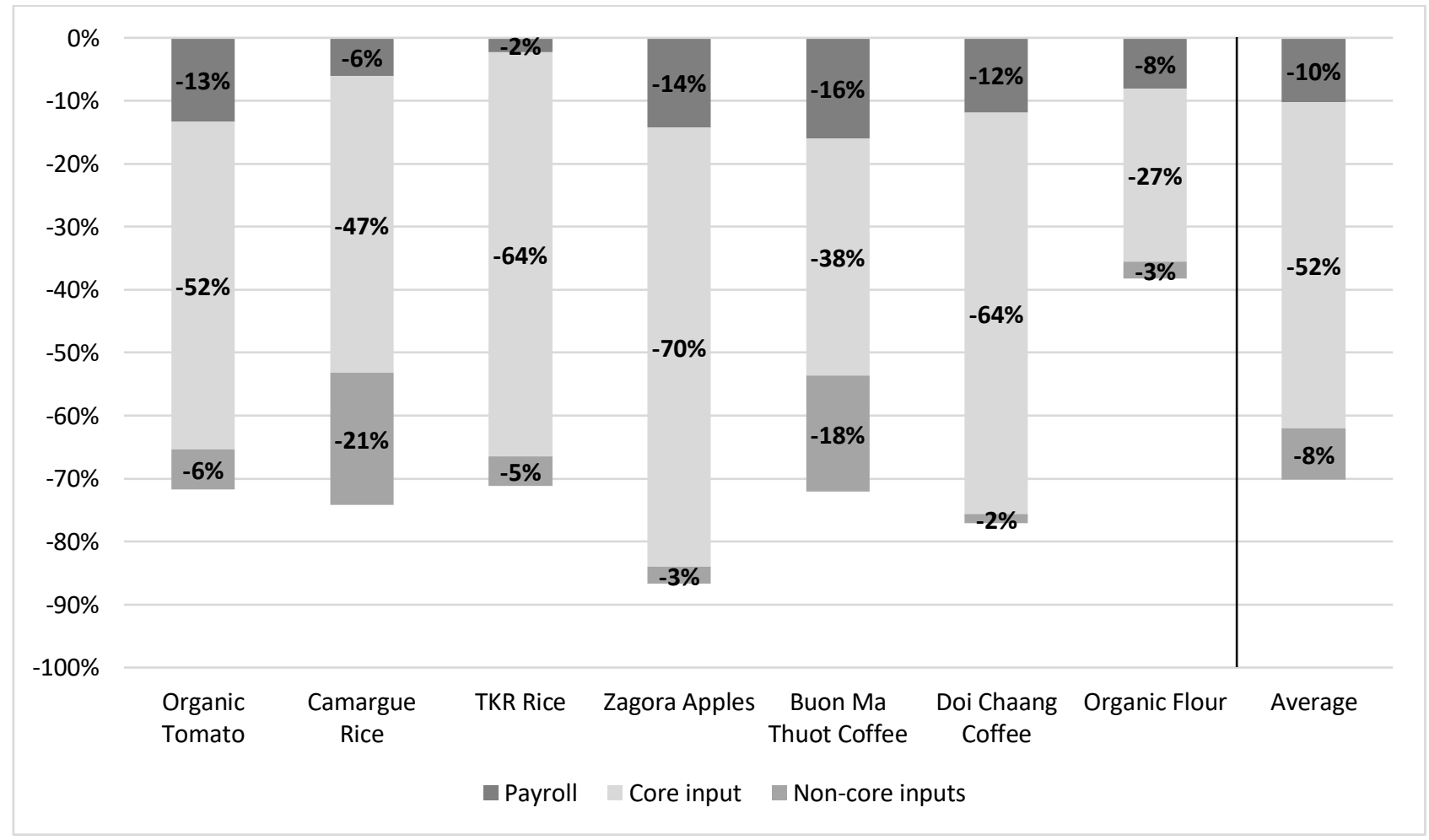


The impact has been measured for the three main costs sustained within the supply chain: payroll, core input costs, and non-core input costs. Figure 5 shows the simulation results, where the total negative variation resulting from the summation of every single reduction corresponds to the percentage reduction to apply to the current local multiplier to obtain a local multiplier equal to 1, i.e. no local economy impact. According to the "no-local contribution" scenario, the core input expenditure appears as the most important element driving the local economy impact. This means that the geographical location of core input suppliers represents a key risk of local multiplier decrease for all FQS products. The second most important risk is payroll for four out of seven products and non-core input expenditure for the others.

\subsection{Animal sector}

For five out of eight products, the local multiplier for animal FQS products reaches very high values, in some cases very close to 3 (Figure 6). As mentioned above, a local multiplier value of 3 means that all the financial flows along the three rounds are retained within the local area. Ternasco d'Aragon, for instance, exhibits a local multiplier of 2.97, i.e. almost every (first- and second-tier) suppliers are local. Unlike vegetal products, the animal sector shows a sort of dichotomy in local multiplier values: most of FQS products are characterized by very high index value, while the other cases present very low values or below 2 . This index heterogeneity within this group of products exacerbates in the case of Gyulai sausage, where raw material originates far away from the place where the meat is processed, and for Ternasco d'Aragon, where all the inputs are local. This is an effect of the code practice rules, which allow, as in the case of Gyulai sausage, the use of raw material coming from outside the region where the meat is processed, while for Ternasco d'Aragon lamb meat originates within the local area.

Figure 6. Local multiplier indicator for FQS and reference (REF) products - Animal sector

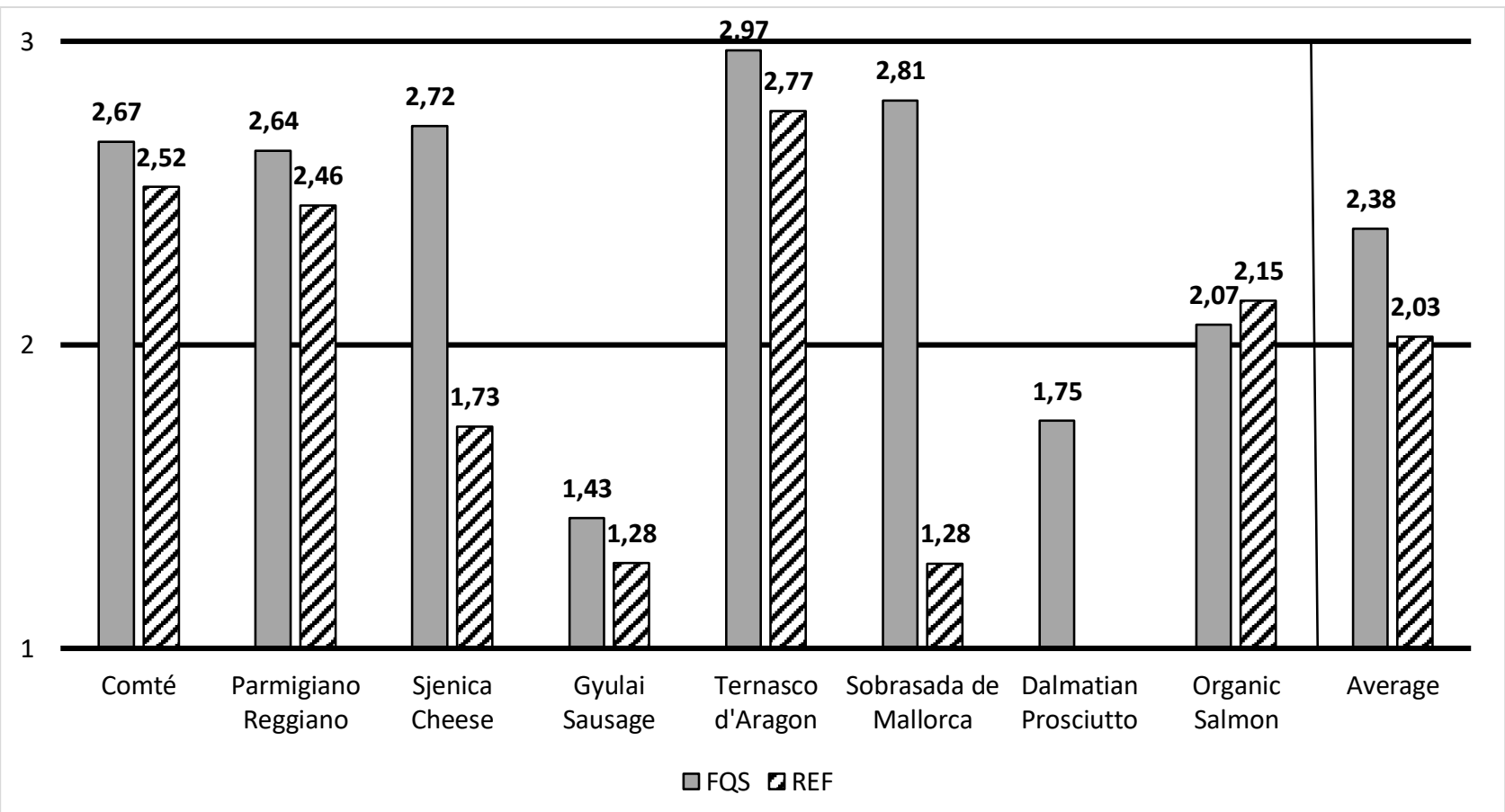

The average value of local multiplier for FQS products and their references is above 2, with a higher value for FQS than its reference for all the products except for Organic Salmon. The average difference between FQS products and their reference is $18 \%$, while the median difference is $24 \%$. This is a consequence of the higher local multiplier variability for the animal productions than for the vegetal ones. The products exhibiting the highest difference with respect to their references are Sobrasada de Mallorca, with a local multiplier more 
than double of its reference, and Sjenica cheese, with a local multiplier for FQS $52 \%$ higher than the reference product (Figure 7). The budget share associated with the core and other intermediate inputs remaining within the local area, both for first and second-tier suppliers, is much lower in the case of non-PGI cheese. Because of information confidentiality issues, it was not possible to calculate the local multiplier for the reference product of Dalmatian Prosciutto, but it is likely much higher than the FQS product as pork meat is locally sourced whereas it is imported from Hungary and Austria in the case of PGI product. Overall, animal products seem to perform better than the vegetal products, which is again consistent with transport costs, likely higher for animals than for vegetal products.

Figure 7. FQS variations in local multiplier with respect to the reference - Animal sector

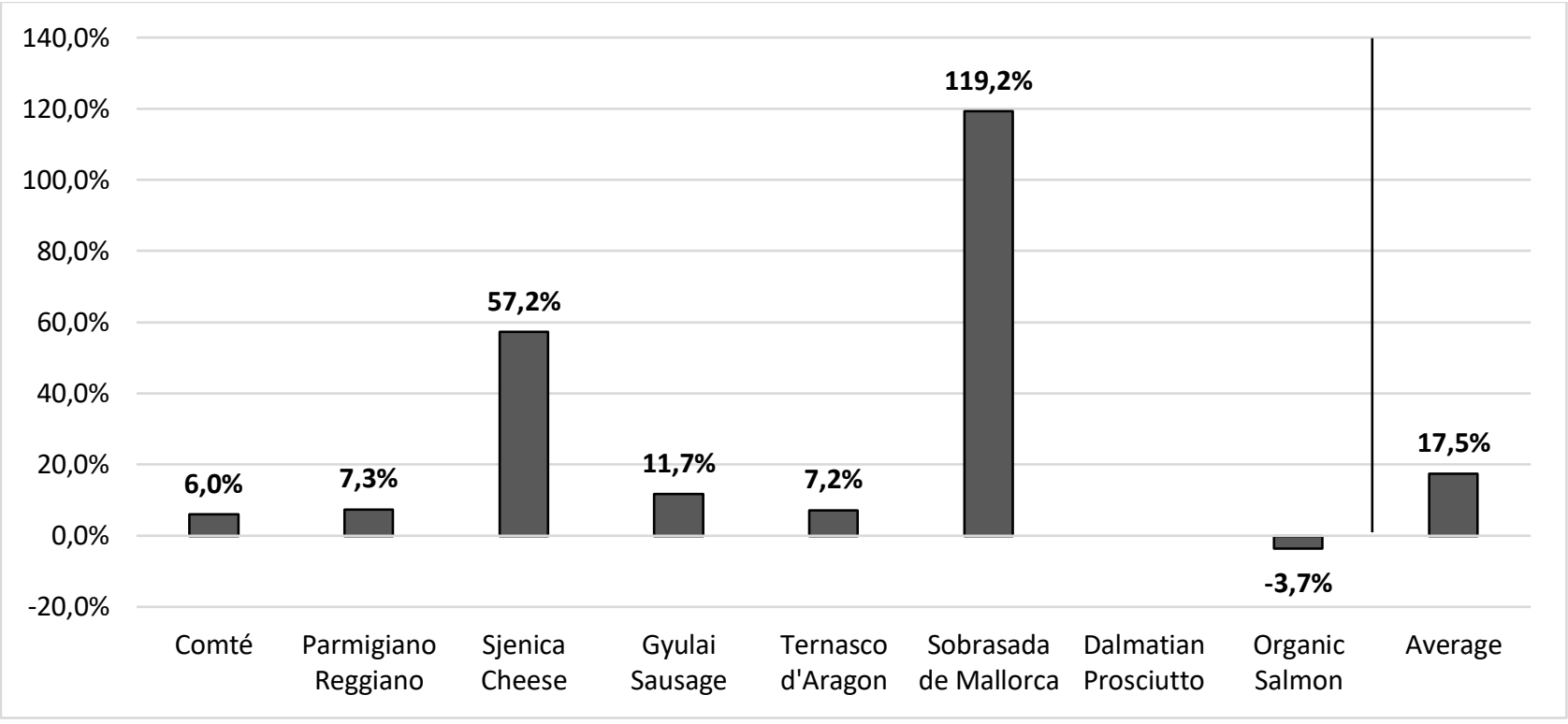

Figure 8. Round composition - Animal sector

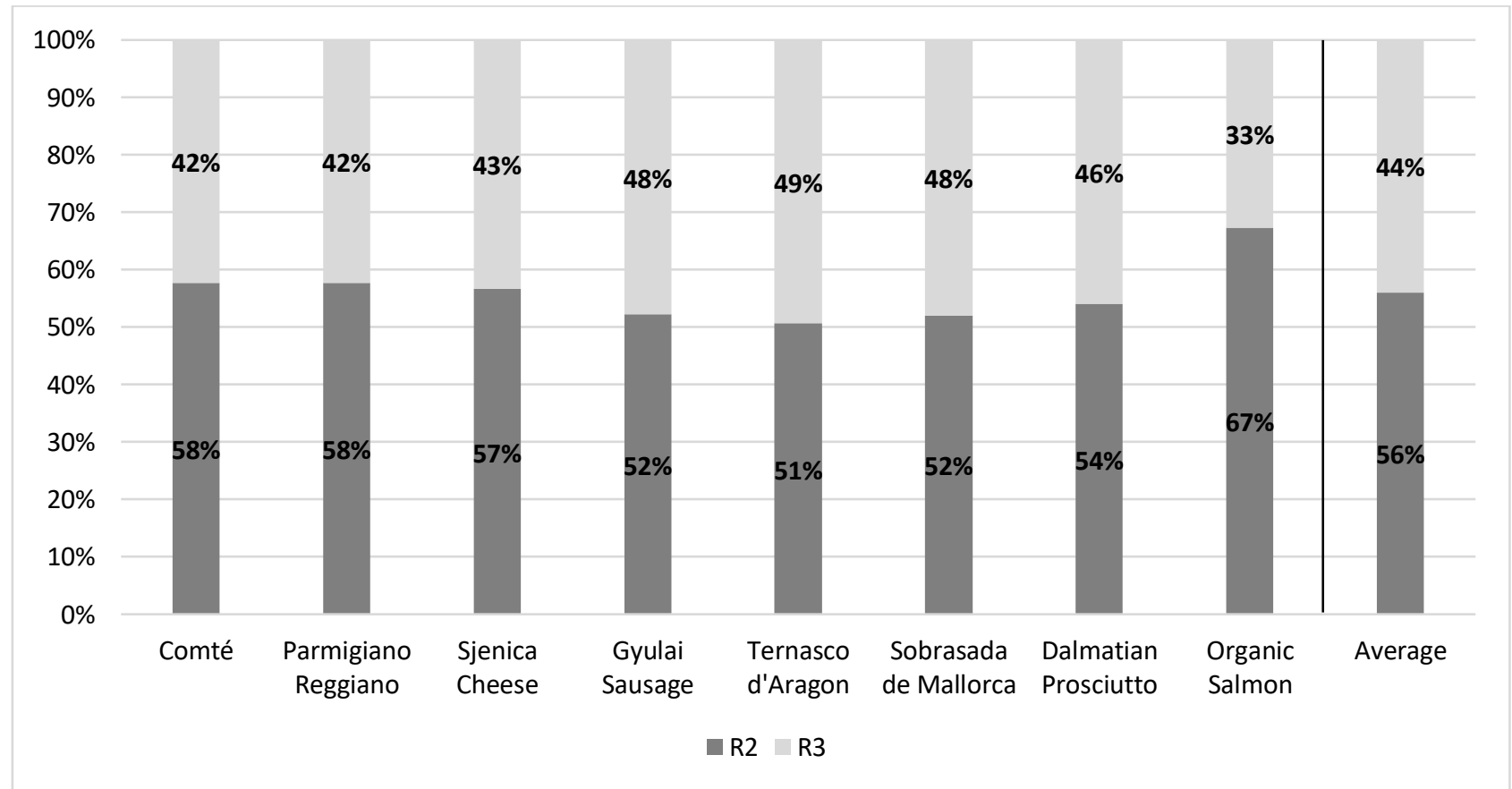


As for vegetal productions, the round composition of the animal sector is evenly distributed between round 2 (suppliers to the processing plants) and round 3 (suppliers to the farms, Figure 8 ). Also in this case, round 2 retained most of the local economy impact, while in round 3 part of the financial flows originating from the second round is leaked. On average, the second round contributes to the local financial flows for $55 \%$ of the entire extra-value generated at local level by the initial budget, while the third round accounts for the remaining $45 \%$.

Figure 9. Local multiplier determinants - Animal sector

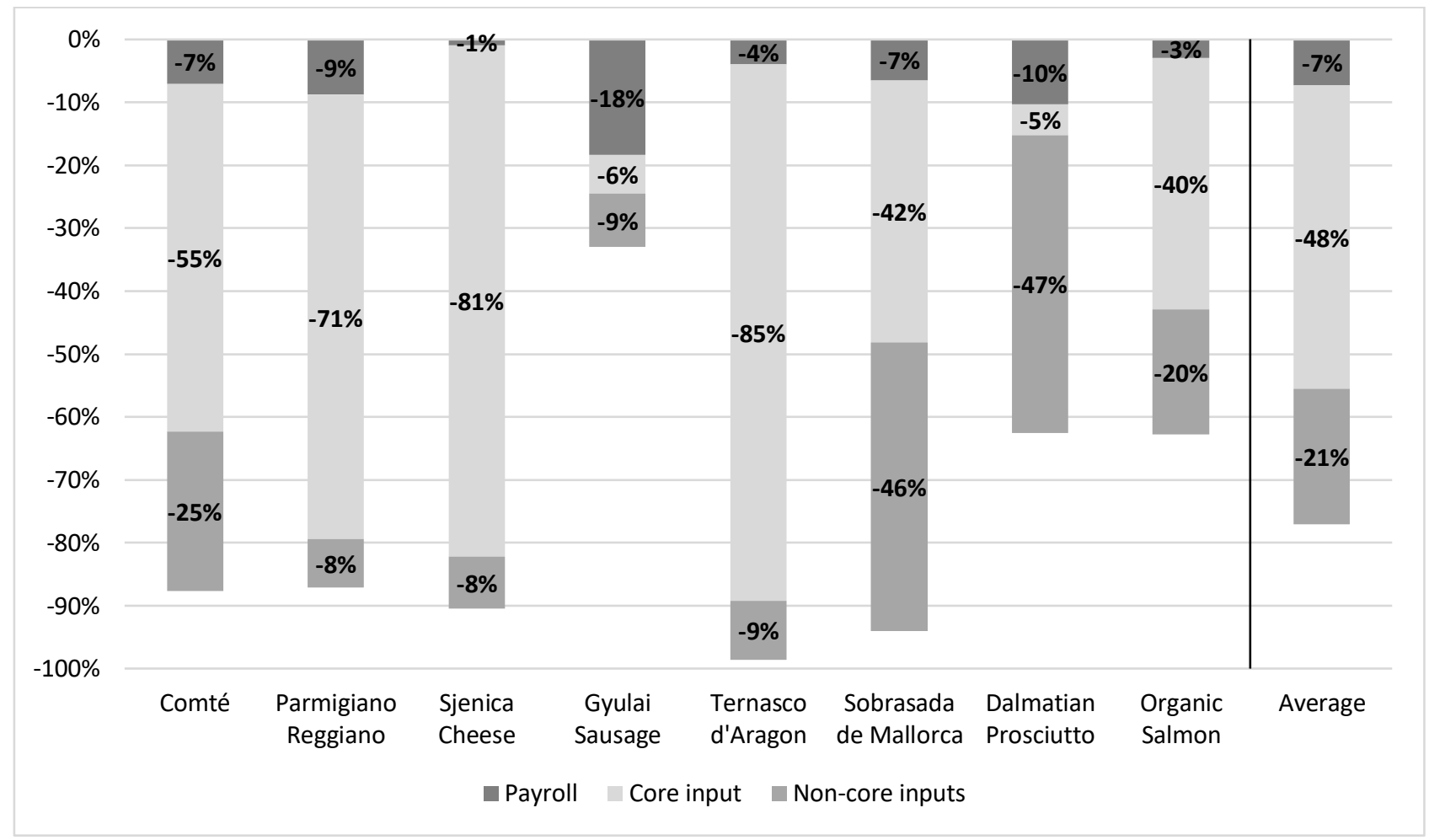

The main risk of deterioration of the local multiplier indicator is not unique across products (Figure 9). For five out of eight products, the main risk for the positive local economy impact relates to the core input expenditure. Therefore, the location of raw material suppliers, i.e. farmers, plays the most important role in defining the contribution to the local economy. In the case of Sjenica cheese and Ternasco d'Aragon, the core input contribution is above $80 \%$. On the contrary, for Gyulai sausage and Dalmatian Prosciutto, the core input expenditure represents the minor determinant in the local multiplier. As mentioned above, the meat suppliers for Gyulai sausage and Dalmatian Prosciutto are non-local. It is noteworthy that for Gyulai sausage the main driver is the staff payroll, while for Dalmatian Prosciutto is the non-core input expenditure. This difference could be due to the production technology and the share of local non-core input costs: more labour intensive for the Gyulai sausage process and more local non-core input suppliers for Dalmatian Prosciutto.

\subsection{Comparison by product category}

Figure 9 shows the distribution of the local multipliers by category of product. The median of the local multiplier for the animal sector is higher than for the vegetal sector (Figure 10). The median difference is $15 \%$. The higher local multiplier for the animal sector is characterised also by a higher variability: the standard deviation for the animal sector 0.54 , while for the vegetal sector 0.32 . Therefore, the local multiplier for animal FQS products is more heterogeneous than for the vegetal one. 
Among the FQS products, PDO labelled products returned the highest local economy impact (median=2.64). This is clearly a consequence of the code of practice that requires for this type of FQS a very close linkage with the territory of origin. This is the case of Parmigiano-Reggiano and Comté, where around dairies and dairy farms a local economic texture comprising agricultural input sellers and dairy support service providers has been stabilized and strengthened over time. The local economic impact of PGI and organic products is $5 \%$ and $22 \%$ lower than for PDOs respectively (Table 2). The indicator variability is higher for PGI products, where the animal-based products represent the majority, than PDO and organic products.

Figure 10. Box-plot of the local multipliers by product category*

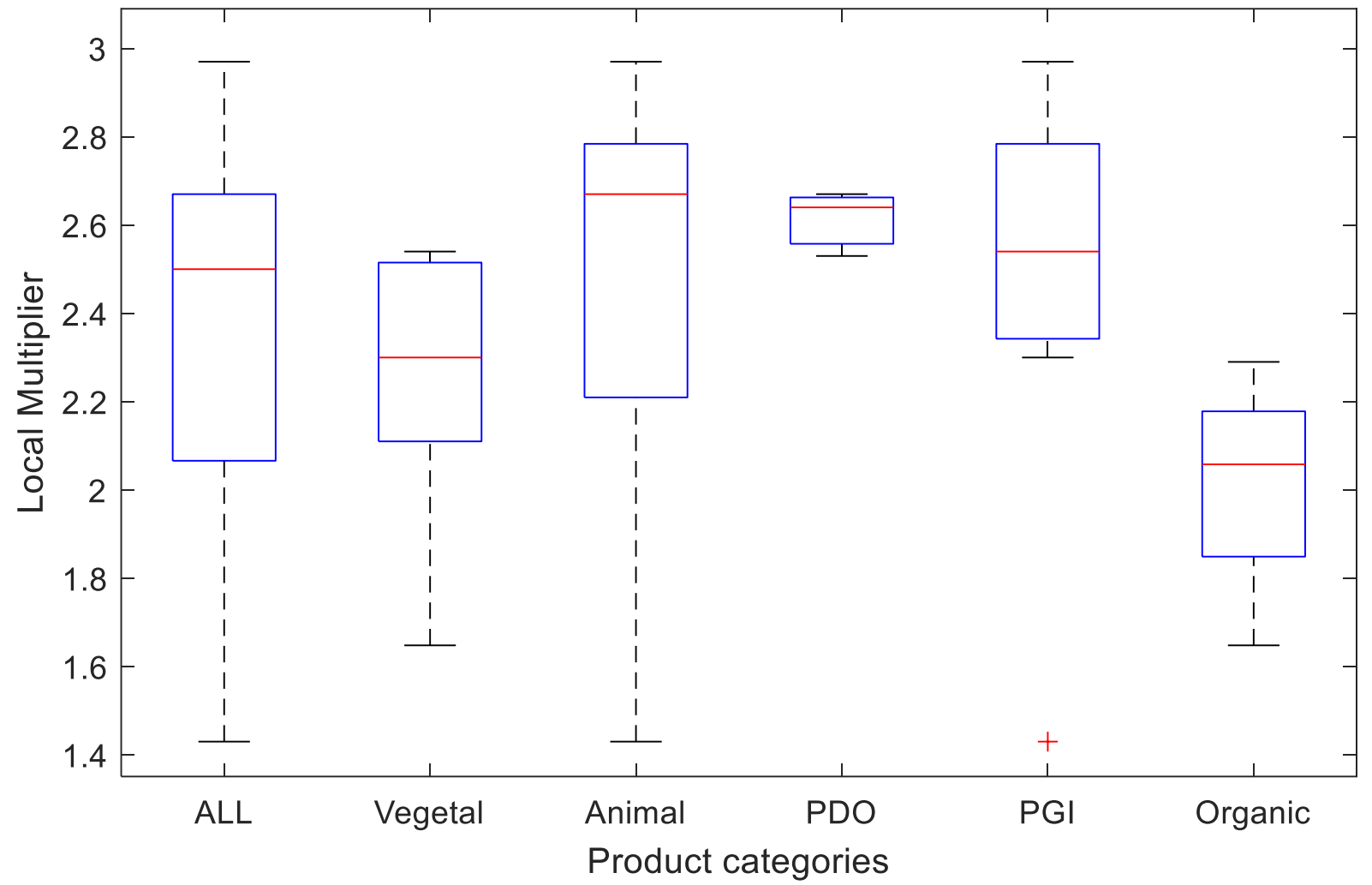

* The central mark indicates the median, and the bottom and top edges of the box indicate the 25th and 75th percentiles, respectively. The whiskers extend to the most extreme data points not considered outliers, and the outliers are plotted individually using the 't' symbol.

By comparing the medians for the FQS products and those obtained for the reference products, FQS products returned a local economic impact $16 \%$ higher than the reference ones. Within the overall result, PGI products exhibited the largest difference together with the animal production category. Processed meat products are the main responsible for this result. In particular, the local multiplier of Ternasco d'Aragon and Sobrasada de Mallora is very close to 3, while the reference products of Sobrasada de Mallorca and Gyulai sausage exhibit a very low local multiplier (about 1.3 for both). The Wilcoxon signed-rank test confirms that the median difference for animal and PGI products is significantly different from zero at the $5 \%$ significance level, while the Kruskal-Wallis test indicates a significant difference for PGI ( $p$-value $=0.0845$ ) at the $10 \%$ of significance level but not for animal products ( $p$-value $=0.11$ ) $($ Table 2$)$.

In the case of vegetal products, the local economic advantage due to FQS is 7\% higher than the reference products. However, the local multiplier for both products is quite high and the discrepancy is not very large ( $53 \%$ of the products show a median difference between $0 \%$ and $10 \%$ ). These results can be explained by i) the high incidence of transportation costs that prevents raw material provision from distant production places and ii) a shared processing technology. For instance, organic and conventional processed tomatoes share the same technology and, generally, they are processed in the same company. The required expertise and technology endowments are applicable for both products, so that food industries can benefit from 
relevant economies of scope (Chaddad and Mondelli, 2013). Beyond the previous considerations, the KruskalWallis test does not indicate any significant difference between the vegetal sector and the rest of the cases ( $p$-value $=0.41)$.

For PDO products, the median difference is $6 \%$ with a range between $2 \%$ and $7 \%$. This set comprises three FQS products: Comté, Parmigiano-Reggiano, and Zagora apple. These FQS products share with their standard counterpart the local source of the main inputs along the supply chain. More specifically, the local origin of the raw material (cow milk and apples) seems to represent a quality feature for the reference product as well as the FQS product. The non-FQS cheese linked to Parmigiano-Reggiano is obtained using milk produced by dairy farms in the areas surrounding the cheese factory. Firms communicate this aspect of the production organisation as an important component of the intrinsic quality of the final product. In this respect, food industries try to intercept the consumers' positive perception about and attitude toward local foods (Feldmann and Hamm, 2015) for exploiting a competitive advantage in the food markets. The fact that the median difference is not significantly different from zero means that for this very limited sample of PDO products the impact on the local economy is very similar to the corresponding standard-reference products.

Table 2. Differences in local multiplier by product category

\begin{tabular}{|c|c|c|c|c|c|c|c|c|c|}
\hline $\begin{array}{l}\text { Product } \\
\text { categories }\end{array}$ & $\begin{array}{c}\text { no. of } \\
\text { products }\end{array}$ & Median & $\begin{array}{c}\text { Standard } \\
\text { deviation } \\
\text { for FQS }\end{array}$ & $\begin{array}{l}\text { Median } \\
\text { difference } \\
\text { (FQS-REF) }\end{array}$ & $\begin{array}{l}\text { Min / Max } \\
\text { difference }\end{array}$ & $\begin{array}{c}\text { Share of } \\
\text { cases } \\
\text { with } \\
\text { negative } \\
\text { difference }\end{array}$ & $\begin{array}{c}\text { Share of } \\
\text { cases } \\
\text { with } \\
\text { difference } \\
>10 \%\end{array}$ & $\begin{array}{c}\text { Wilcoxon* } \\
\text { p-value }\end{array}$ & $\begin{array}{l}\text { Kruskal- } \\
\text { Wallis** } \\
\text { p-value }\end{array}$ \\
\hline Vegetal & 7 & 2.30 & 0.321 & $6.9 \%$ & {$[-23 \% ;+13 \%]$} & $14 \%$ & $29 \%$ & 0.2969 & 0.4062 \\
\hline Animal & 7 & 2.66 & 0.538 & $24.4 \%$ & [-4\%;+119\%] & $14 \%$ & $43 \%$ & 0.0313 & 0.1102 \\
\hline PDO & 3 & 2.64 & 0.074 & $6.0 \%$ & {$[+2 \% ;+7 \%]$} & $0 \%$ & $0 \%$ & 0.2500 & 0.0495 \\
\hline PGI & 7 & 2.51 & 0.507 & $25.1 \%$ & [+6\%;+119\%] & $14 \%$ & $57 \%$ & 0.0156 & 0.0845 \\
\hline Organic & 4 & 2.06 & 0.267 & $0.4 \%$ & {$[-23 \% ;+12 \%]$} & $50 \%$ & $25 \%$ & 1.0000 & 1.0000 \\
\hline All & 14 & 2.47 & 0.439 & $16.3 \%$ & [-23\%;+19\%] & $14 \%$ & $36 \%$ & 0.0129 & 0.0808 \\
\hline
\end{tabular}

* We apply the Wilcoxon signed-rank test on paired samples to assess the significance level of the median differences

** We apply the Kruskal-Wallis test for the null hypothesis that FQS and reference medians come from the same distribution

Finally, organic products show a slightly positive median difference, although not statistically significant. The analysis of the organic case studies pointed out how organic processors generally rely on non-local products because of the limited amount of raw material from local organic production basins. For instance, in the case of the organic wheat-based flour in France, the amount of money spent for wheat suppliers (farmers) does not remain completely within the local area: just $33 \%$ of the expenditure for wheat suppliers is addressed to local farmers. This means that the local area does not represent a supplier of the organic raw material capable of satisfying the milling industry, such that it is necessary to obtain organic wheat from farmers located outside the local area. This may however be specific to the vegetal sector which dominates our organic sample ( 3 out of 4 cases). Indeed, in the animal sector, the organic technical specifications emphasize the territorial link between feed, farms, and processing plants which would likely translate into a higher local multiplier than the reference products.

\section{Discussion}

\subsection{FQS Vs. Reference}


It is commonly recognised that FQS products exert an important role in linking local and non-local actors for creating the conditions for fostering socio-economic growth in rural areas according to a mixed exogenous/endogenous development model (Tregear et al., 2007). FQS configures as a means of connecting rural areas with cities, stabilizing rural communities and employment, promoting environmental friendly practice, and retaining economic resources (i.e. income, tax revenues) within the local economy (Bramley and Kirsten, 2007; Cei et al., 2018; Goodman, 2004; Kitchen and Marsden, 2009; Raimondi et al., 2018; van der Zanden et al., 2017; Vandecandelaere, 2014; Vandecandelaere et al., 2010). In this study, the LM3-based indicator is helpful to clarify to what extent FQS contributes to the local economy, and if FQS performs better than standard reference food products at local level.

The results obtained in this paper revealed a clear difference between the local economy effects produced by animal and vegetal products. PDO and PGI animal products (particularly cheese and Spanish processed meat) exhibit a significant local multiplier effect, thanks to the local source of raw material. Although vegetal FQS products exceed the intermediate local multiplier level, animal products perform better $(+15 \%)$. It is possible to argue that the comparative advantage of the FQS animal products can be due to specific restrictions imposed by the code of practice in relation to breeding location and animal feed source. This latter specification traces a strong linkage of the FQS produce with its territory. For example, ParmigianoReggiano production rules require that a significant proportion of animal feed (at least $75 \%$ ) is produced at the local level. Similar rules apply also for Comté, Sjenica cheese, Ternasco d'Aragon, and Sobrasada de Mallorca. On the contrary, if the code of practice does not specify a clear linkage between territory and farming activity, the multiplier effect becomes very low. This is the case of Dalmatian prosciutto and Gjiulai sausage with local multipliers lower than most part of the reference animal products. This is an important finding for designing new FQS strategies beneficial for local economies and, mainly, for rural areas.

FQS (PDO and PGI) animal products returned also a high positive discrepancy in local multiplier with respect to their reference counterparts $(+24 \%)$. The non-parametric test of Wilcoxon confirms the statistical significance of this discrepancy. It is evident that the constraints introduced by the FQSs through the code of practices imply greater costs of production for the supply chain, mainly spent within bounded areas. Without a code of practices imposing territorial production linkages, "localness" is no more embedded in seeking raw material; therefore, operators purchase fresh meat where it is possible to achieve the target quality advantage at a minimum cost. The relatively low incidence of transportation costs allows importing fresh meat from non-local areas. Consequently, the financial flows due to the transactions with non-local suppliers shift from the local economy to elsewhere.

Despite the distinction in farming systems, the local economy contribution of the organic and non-organic productions seems to be substantially equivalent. The median local multiplier for both is not very high but it exceeds the level of 2 so that 1 euro spent by the downstream holding generates more than 1 euro of financial flow along the supply chain within the local area. The statistical test confirms that the median difference between the two types of products is not significant. This finding was also achieved in the study of Lobley et al. (2009) about the contribution of organic farming to rural development. They did not notice dissimilar rural development potential of organic and non-organic farms. This means that the proportion of local sales and purchases is quite similar as observed for our sample. The focus on farms for organic productions is preeminent, because of the peculiarity of the farming system, while the downstream processes do not differ depending on whether the product is organic or conventional.

\subsection{Risks of local multiplier decrease in FQS}

Besides the evident dependence of the indicator on the supply chain structure, the decomposition of the local multiplier indicates the importance of the geographical distribution of first- and second-tier suppliers within the territory. In particular, core input suppliers, i.e. agricultural holdings, play a crucial role in spreading the beneficial economic effects within the local areas. Farms in turn activate a series of local actors through a process of local transactions contributing to further increase and stabilize the flow of money within rural areas. Evidence suggests that farms hire fewer workers (because of the relevant family contribution to farm activity) than in the other firms of the supply chain, but they exhibit higher input purchase at the local level, 
which entails that they promote economic sustainability (by stabilizing income and occupation) in other sectors of the local economy. The greater potential for the core input suppliers in stimulating the local economy and, thus, rural development (growth) has been discovered for all the FQS products except 2 (Gyulai sausage and Dalmatian Prosciutto). This finding may represent an important input for addressing the rural policy and, more generally, the public intervention to support agri-food supply chains in rural areas. Therefore, the economic linkages among the different actors, the magnitude of the spill-over effects along the supply chain make up key information for policy makers (Moretti, 2010). As Courtney et al. (2007) argue, since agricultural policies exert a strong influence on local economies, the role and the economic linkage of the different actors within rural areas should be properly investigated.

\subsection{Methodological issues and limits}

This study investigates the local economic spill-over effects of a small sample of FQS products. Certainly, our findings cannot be immediately extended to all EU FQS products, because of the difference in the geographical context, the supply chain composition, the production technology, and the network of stakeholders. Nevertheless, what this study proposes is i) a straightforward procedure that can be adopted as a support for policy making, ii) the way of handling the outcomes, and iii) detecting the patterns of local economy linkages.

NEF asserts that LM3 is a "quick and simple" procedure to apply (Sacks, 2002). However, implementing our LM3-based methodology was particularly time consuming, mainly due to the data collection phase which required an important effort by data collectors in identifying first- and second-tier suppliers along the three rounds and the related, primary and secondary, information to feed the assessment model. This is the reason why LM3 is usually calculated on a sample rather than on the entire population (Thatcher and Sharp, 2008). The main difficulty in the data collection phase deals with the identification of the relevant information for round 3, i.e. the second-tier supplier monetary flows, where it is frequent to face problems of sensitive or inaccessible information. In several cases, missing primary information obliged data collectors to turn to "expert knowledge" through stakeholder interviews. Consequently, the quality and reliability of the data for the round 3 may be affected by personal assumptions and by unavoidable misinterpretations. As some authors suggest, for improving the reliability of the LM3 results, the third round should be removed while keeping the first two rounds (Mitchell and Lemon, 2019; Thatcher and Sharp, 2008). However, this alternative "LM2" set-up may miss a non-negligible contribution to the local economy by the re-spending. In this study, on average, round 3 accounted for about $40 \%$ of the overall local economy effect.

FQS products are experiencing high market price variabilities affecting the economic sustainability of the entire supply chain. Several FQS products face market favourable and adverse economic cycles depending on market factors, such as the supply evolution, the trend in domestic demand and export, and stock amounts (Sckokai et al., 2013). In particular, negative economic situations can severely affect the capacity of FQS to stimulate the local economy. In this respect, the local multiplier is a static indicator of the local economy impact whose accuracy is limited to the time-span assumed in the analysis. Changes in the economic frame and market factors would require a new assessment.

\section{Conclusions}

This paper is aimed at evaluating the economic spill-over effect induced by FQS products within a local area through the calculation of a local multiplier derived from LM3 methodology. To evaluate the effective contribution within the local area we compare each FQS product with its equivalent standard counterpart. Local multiplier allows us to track the financial flows converging within the local area at the different levels of the supply chain so that we can measure the FQS product role in local economic activation. In turn, the LM3-based indicator helps to clarify to what extent FQS can produce benefits within the local economy, and if FQS performs better than standard reference food products at local level. 
The results show that the overall local impact of the FQS products is higher than their equivalent counterpart confirming the role of FQS products in sustain socio-economic viability in rural areas. Nevertheless, a heterogeneity depending on the product categories arose from the results. In particular, animal products perform better than vegetal ones. The reason can be found in the code of practice of animal FQS products that comprises, in general, more actors and processing phases than in the case of the vegetal product supply chain, with the consequence that more local-input restrictions are imposed along the supply chain. This strong linkage with the territory established by the code of practice applies for the PDO products but not completely for the PGI products, for which the connections with the territory is somewhat weak. In the case of organic products, the local economy strengthening, thanks to the financial flow generated by the FQS supply chain, is not dissimilar to the conventional one. The statistical tests confirm this achievement, determined by a very similar proportion of local expenditure for organic and conventional products.

Our findings recommend the use of the economic spill-over effect assessment for developing new FQS strategies and policies aiming at fostering local rural areas or prevent their decline. Our conclusion that PDO and PGI products have a quite high positive effect toward the local economy, whilst organic products have a lower impact and not significantly different from the conventional products, may lead policy makers to focus on the role of organic production systems in providing economic resources and promote socio-economic development in rural areas. Beyond the organic case, our analysis may encourage local FQS supply chain players to find new vertical or horizontal integration patterns for the FQS supply chain for creating more and new economic opportunities at local level.

\section{References}

Balamou, E., Psaltopoulos, D., 2006. Nature of rural-urban interdependencies and their diffusion patterns in Southern Greece: An interregional SAM model. Rev. Urban Reg. Dev. Stud. 18, 60-83. https://doi.org/10.1111/j.1467-940X.2006.00110.x

Barczak, A., Bellassen, V., Arfini, F., Brečić, R., Giraud, G., Majewski, E., Tocco, B., Tregear, A., Vitters $\varnothing$, G., 2016. Selection of Case Study Regions and Cases for Impact Analysis, Strength2Food - Deliverable 3.3. https://www.strength2food.eu/2016/11/29/selection-.

Bellassen, V., Giraud, G., Hilal, M., Arfini, F., Barczak, A., Bodini, A., Brennan, M., Drut, M., Gorton, M., Majewski, E., Muller, P., Tocco, B., Tregear, A., Veneziani, M., Vitterso, G., 2016. Methods and Indicators for Measuring the Social, Environmental and Economic Impacts of Food Quality Schemes, Short Food Supply Chains and Varying Public Sector Food Procurement Policies on Agri-Food Chain Participants and Rural Territories. Strength2Food - Deliverable 3.2. https://www.strength2food.eu/2016/10/03/methodological-handbook/.

Bengo, I., Arena, M., Azzone, G., Calderini, M., 2016. Indicators and metrics for social business: a review of current approaches. J. Soc. Entrep. 7, 1-24. https://doi.org/10.1080/19420676.2015.1049286

Bramley, C., Kirsten, J.F., 2007. Exploring the economic rationale for protecting geographical indicators in agriculture. Agrekon. https://doi.org/10.1080/03031853.2007.9523761

Březina, D., Hlaváčková, P., 2016. Quantification of the influence of the Training Forest Enterprise Masaryk Forest Krrtiny on the local economy of the region. J. For. Sci. 62, 245-252. https://doi.org/10.17221/117/2015-JFS

Burke, C., King, A., 2015. Generating social value through public sector construction procurement, in: Raidén, A., Aboagye-Nimo, E. (Eds.), Proceedings of the 31st Annual Conference - Association of Researchers in Construction Management (ARCOM). ARCOM, Association of Researchers in Construction Management, Reading, pp. 387-396.

Cei, L., Defrancesco, E., Stefani, G., 2018. From geographical indications to rural development: A review of the economic effects of European Union policy. Sustain. https://doi.org/10.3390/su10103745

Chaddad, F.R., Mondelli, M.P., 2013. Sources of firm performance differences in the US food economy. J. 
Agric. Econ. 64, 382-404. https://doi.org/10.1111/j.1477-9552.2012.00369.x

Courtney, P., Errington, A., 2000. The Role of Small Towns in the Local Economy and Some Implications for Development Policy. Local Econ. J. Local Econ. Policy Unit 15, 280-301. https://doi.org/10.1080/026909400750068013

Courtney, P., Mayfield, L., Tranter, R., Jones, P., Errington, A., 2007. Small towns as "sub-poles" in English rural development: Investigating rural-urban linkages using sub-regional social accounting matrices. Geoforum 38, 1219-1232. https://doi.org/10.1016/j.geoforum.2007.03.006

Courtney, P., Mills, J., Gaskell, P., Chaplin, S., 2013. Investigating the incidental benefits of Environmental Stewardship schemes in England. Land use policy 31, 26-37. https://doi.org/10.1016/j.landusepol.2012.01.013

Dowler, E., Caraher, M., Michaels, S., Diamond, N., Delow, E., Cousens, C., 2003. The value and potential of local food initiatives in the West Midlands region A report to Advantage West Midlands Woodland f3the Foundation for Local Food Initiatives.

https://www.researchgate.net/profile/Elizabeth_Dowler/publication/255653937_The_Value_and_Pot ential_of_Local_Food_Initiatives_in_the_West_Midlands_Region/links/00b7d53a878c3c316e000000/ The-Value-and-Potential-of-Local-Food-Initiatives-in-the-West-Midlands.

Feldmann, C., Hamm, U., 2015. Consumers' perceptions and preferences for local food: A review. Food Qual. Prefer. 40, 152-164. https://doi.org/10.1016/j.foodqual.2014.09.014

Goodman, D., 2004. Rural Europe Redux? Reflections on Alternative Agro-Food Networks and Paradigm Change. Sociol. Ruralis 44.

Harrison, L., 1993. The impact of the agricultural industry on the rural economy - tracking the spatial distribution of the farm inputs and outputs. J. Rural Stud. https://doi.org/10.1016/07430167(93)90007-7

Hyytiä, N., 2014. Rural-Urban Multiplier and Policy Effects in Finish Rural Regions: an Inter-Regional Sam Analysis. Eur. Countrys. 6, 179-201. https://doi.org/10.2478/euco-2014-0010

Johns, P.M., Leat, P.M.K., 1987. The application of modified GRIT input-output procedures to rural development analysis in Grampian Region. J. Agric. Econ. 38, 242-256. https://doi.org/10.1111/j.1477-9552.1987.tb01044.x

Kitchen, L., Marsden, T., 2009. Creating sustainable rural development through stimulating the ecoeconomy: Beyond the eco-economic paradox? Sociol. Ruralis. https://doi.org/10.1111/j.14679523.2009.00489.x

Leontief, W., 1974. Linked references are available on JSTOR for this article : Structure of the World Economy Outline of a Simple Input-Output Formulation. Am. Econ. Rev. 64, 823-834.

Lobley, M., Butler, A., Reed, M., 2009. The contribution of organic farming to rural development: An exploration of the socio-economic linkages of organic and non-organic farms in England. Land use policy 26, 723-735. https://doi.org/10.1016/j.landusepol.2008.09.007

Mancini, M.C., Arfini, F., 2018. Short supply chains and protected designations of origin: The case of parmigiano reggiano (Italy). Ager. https://doi.org/10.4422/ager.2018.11

Marasteanu, I.J., Jaenicke, E.C., 2018. Renewable Agriculture and Food Systems Economic impact of organic agriculture hotspots in the United States. Renew. Agric. Food Syst. 1-22. https://doi.org/10.1017/S1742170518000066

Marsden, T., Banks, J., Bristow, G., 2000. Food Supply Chain Approaches: Exploring their Role in Rural Development. Sociol. Ruralis 40, 424-438. https://doi.org/10.1111/1467-9523.00158

McDonald, A., Boden, P., 2012. Northern gas network: Regional economic impact. Edge Analytics, Leeds. https://www.northerngasnetworks.co.uk/wp-content/uploads/2017/04/Appendix20-Regional- 
Economic-Impacts.pdf.

Mitchell, A., 2017. The local economic multiplier effect of edibLE16: A supply chain survey. https://sustainableharborough.co.uk/wp-content/uploads/2019/05/SH-project-report-edibLE16-LM32017.pdf.

Mitchell, A., Lemon, M., 2019. Using the LM3 method to evaluate economic impacts of an on-line retailer of local food in an English market town. Local Econ. 34, 51-67. https://doi.org/10.1177/0269094219826569

Moretti, E., 2010. Local Multipliers. Am. Econ. Rev. 100, 1-7. https://doi.org/10.1257/aer.100.2.373

Morris, C., Buller, H., 2003. The local food sector: A preliminary assessment of its form and impact in Gloucestershire. Br. Food J. https://doi.org/10.1108/00070700310497318

Pangbourne, K., Roberts, D., 2015. Small Towns and Agriculture: Understanding the Spatial Pattern of Farm Linkages. Eur. Plan. Stud. 23, 494-508. https://doi.org/10.1080/09654313.2013.872231

Pieters, J., 2010. Growth and Inequality in India: Analysis of an Extended Social Accounting Matrix. World Dev. 38, 270-281. https://doi.org/10.1016/j.worlddev.2009.09.006

Potts, D., 2008. Assessing the impact of regeneration spending: lessons from the United Kingdom and the wider world. Educ. Knowl. Econ. 2, 213-222. https://doi.org/10.1080/17496890802426238

Psaltopoulos, D., Balamou, E., Thomson, K.J., 2006. Rural-urban impacts of CAP measures in Greece: An inter-regional SAM approach. J. Agric. Econ. 57, 441-458. https://doi.org/10.1111/j.14779552.2006.00059.x

Raimondi, V., Curzi, D., Arfini, F., Olper, A., Aghabeygi, M., 2018. Evaluating Socio-Economic Impacts of PDO on Rural Areas, in: 7th AIEAA Conference "Evidence-Based Policies to Face New Challenges for AgriFood Systems."

Renting, H., Marsden, T.K., Banks, J., 2003. Understanding alternative food networks: Exploring the role of short food supply chains in rural development. Environ. Plan. A 35, 393-411. https://doi.org/10.1068/a3510

Roberts, D., 1998. Rural-urban interdependencies: Analysis using an inter-regional SAM model. Eur. Rev. Agric. Econ. 25, 506-527. https://doi.org/10.1093/erae/25.4.506

Robison, M.H., 1997. Community input-output models for rural area analysis with an example from central Idaho. Ann. Reg. Sci. https://doi.org/10.1007/s001680050052

Round, J., 2003. Social Accounting Matrices and SAM-based Multiplier Analysis, in: Bourguignon, F., da Silva, L.A.P. (Eds.), Techniques and Tools for Evaluating the Poverty Impact of Economic Policies. Washington, DC, pp. 301-324.

Sacks, J., 2002. The Money Trail: Measuring Your Impact on the Local Economy Using LM3. New Economics Foundation, London.

Sckokai, P., Soregaroli, C., Moro, D., 2013. Estimating Market Power by Retailers in a Dynamic Framework: The Italian PDO Cheese Market. J. Agric. Econ. https://doi.org/10.1111/j.1477-9552.2012.00368.x

Slee, B., 2006. The socio-economic evaluation of the impact of forestry on rural development: A regional level analysis. For. Policy Econ. 8, 542-554. https://doi.org/10.1016/j.forpol.2005.07.006

Smithers, J., Lamarche, J., Joseph, A.E., 2008. Unpacking the terms of engagement with local food at the Farmers' Market: Insights from Ontario. J. Rural Stud. 24, 337-350. https://doi.org/10.1016/j.jrurstud.2007.12.009

Stahmer, C., 2004. Social Accounting Matrices and Extended Input-Output Tables, in: Measuring Sustainable Development: Integrated Economic, Environmental and Social Frameworks. OECD Publishing, Paris, pp. 313-344. 
Thatcher, J., Sharp, L., 2008. Measuring the local economic impact of National Health Service procurement in the UK: An evaluation of the Cornwall Food Programme and LM3. Local Environ. 13, 253-270. https://doi.org/10.1080/13549830701669005

Tregear, A., Arfini, F., Belletti, G., Marescotti, A., 2007. Regional foods and rural development: The role of product qualification. J. Rural Stud. 23, 12-22. https://doi.org/10.1016/j.jrurstud.2006.09.010

USDA, 2008. Farm and Household Interaction With Local and Regional Economies, in: Agricultural Income and Finance Outlook. USDA Economic Research Service, https://downloads.usda.library.cornell.edu/usdaesmis/files/w0892992w/wh246t71n/08612q19q/AIS-12-10-2008.pdf, pp. 68-71.

van der Ploeg, J.D., Renting, H., Brunori, G., Knickei, K., Mannion, J., Marsden, T., de Roest, K., SevillaGuzmán, E., Ventura, F., 2018. Rural Development: From Practices and Policies towards Theory. Rural 40, 201-218. https://doi.org/10.4324/9781315237213-11

van der Zanden, E.H., Verburg, P.H., Schulp, C.J.E., Verkerk, P.J., 2017. Trade-offs of European agricultural abandonment. Land use policy 62, 290-301. https://doi.org/10.1016/j.landusepol.2017.01.003

Vandecandelaere, E., 2014. Geographical indication as a tool for sustainable food systems: importance of a territorial approach, in: Voluntary Standards for Sustainable Food Systems: Challenges and Opportunities. FAO, Rome, pp. 93-104.

Vandecandelaere, E., Arfini, F., Belletti, G., Marescotti, A., 2010. Linking people, places and products. A guide for promoting quality linked to geographical origin and sustainable geographical indications, Quality. FAO, Rome.

Wiedmann, T., 2009. A review of recent multi-region input-output models used for consumption-based emission and resource accounting. Ecol. Econ. https://doi.org/10.1016/j.ecolecon.2009.08.026 
Appendix - List of variables

\begin{tabular}{|c|c|c|c|}
\hline Variable name & Variable relevance & Unit & Brief description \\
\hline R1_turnover & key & $€$ year-1 & Total annual turnover at level R1. \\
\hline R1_wages & key & $\%$ turnover & $\begin{array}{l}\text { Sum of wages paid for family workers and employees at level R1 of the } \\
\text { value chain, including if necessary an approximated fixed hourly } \\
\text { remuneration for (unpaid) family labour }\end{array}$ \\
\hline R1_NCl & key & $\%$ turnover & $\begin{array}{l}\text { Total Cost of Non-Core Input at level R1 (e.g. for Parmigiano-Reggiano, all } \\
\text { the input costs excluding labour and milk). }\end{array}$ \\
\hline R1_Cl & key & $\%$ turnover & $\begin{array}{l}\text { Total cost of Core Input at level R1 (e.g. for Parmigiano-Reggiano, the cost } \\
\text { of milk) }\end{array}$ \\
\hline R1_Tot_staff_la & key & $\%$ & Share of staff at level R1 living in the local area \\
\hline R1_Cl_LA & key & $\%$ & $\begin{array}{l}\text { Share of core input suppliers (level R2) whose headquarter is located in } \\
\text { the local area (e.g. for Parmigiano-Reggiano, the number of milk } \\
\text { producers located in the local area) }\end{array}$ \\
\hline R1_NCl_LA & key & $\%$ & $\begin{array}{l}\% \text { of } \mathrm{NCl} \text { suppliers (level R2) whose headquarter is located in the local } \\
\text { area }\end{array}$ \\
\hline food\&B & complementary & $\%$ & $\%$ of the total household income spent for food and beverage \\
\hline home\&R & complementary & $\%$ & $\%$ of the total household income spent for home rent \\
\hline fuel\&E & complementary & $\%$ & $\%$ of the total household income spent for fuel and energy \\
\hline home_forniture & complementary & $\%$ & $\%$ of the total household income spent for home furniture \\
\hline transport & complementary & $\%$ & $\%$ of the total household income spent for transport \\
\hline dressing & complementary & $\%$ & $\%$ of the total household income spent for dressing \\
\hline free_time & complementary & $\%$ & $\%$ of the total household income spent for free times \\
\hline others_expend & complementary & $\%$ & $\%$ of the total household income spent for others \\
\hline food\&B_LA & key & $\%$ & $\begin{array}{l}\% \text { of the total household income spent IN local area for food and } \\
\text { beverage }\end{array}$ \\
\hline home\&R_LA & key & $\%$ & $\%$ of the total household income spent IN local area for home rent \\
\hline fuel\&E_LA & key & $\%$ & $\%$ of the total household income spent IN local area for fuel and energy \\
\hline home_forniture_LA & key & $\%$ & $\%$ of the total household income spent IN local area for home furniture \\
\hline transport_LA & key & $\%$ & $\%$ of the total household income spent IN local area for transport \\
\hline dressing_LA & key & $\%$ & $\%$ of the total household income spent IN local area for dressing \\
\hline free_time_LA & key & $\%$ & $\%$ of the total household income spent IN local area for free times \\
\hline
\end{tabular}




\begin{tabular}{|c|c|c|c|}
\hline others_expend_LA & key & $\%$ & $\%$ of the total household income spent IN local area for others \\
\hline R2_1_NCinputX & complementary & $\%$ & $\begin{array}{l}\text { \% of the non-core input R2.X suppliers (level R2) located IN local area } \\
\text { (where "X" stands for each non-core input, e.g. electric power, fuel, } \\
\text { transport, storage, etc.) }\end{array}$ \\
\hline R2_2_NCinputX & key & $\%$ & $\begin{array}{l}\% \text { of the non-core input R2.X to level R1 cost on the total cost of the non- } \\
\text { core inputs (where " } X \text { " stands for each non-core input, e.g. electric } \\
\text { power, fuel, transport, storage, etc.) }\end{array}$ \\
\hline R2_3_NCinputX & key & $\%$ & $\begin{array}{l}\% \text { of the non-core input R2.X to level R1 cost due to labour sustained by } \\
\text { suppliers R2 (where " } X \text { " stands for each non-core input, e.g. electric } \\
\text { power, fuel, transport, storage, etc.) }\end{array}$ \\
\hline R2_4_NCinputX & complementary & $\%$ & $\begin{array}{l}\text { \% of the non-core input R2.X to level R1 cost due to other inputs (labour } \\
\text { excluded) sustained by suppliers R2 (where "X" stands for each non-core } \\
\text { input, e.g. electric power, fuel, transport, storage, etc.) }\end{array}$ \\
\hline R2_5_NCinputX & key & $\%$ & $\begin{array}{l}\text { \% of labour costs related to R2 suppliers of the input R2.X with HQ IN the } \\
\text { local area (where "X" stands for each non-core input, e.g. electric power, } \\
\text { fuel, transport, storage, etc.) }\end{array}$ \\
\hline R2_6_NCinputX & key & $\%$ & $\begin{array}{l}\text { \% of labour costs related to R2 suppliers of the input R2.X spent IN local } \\
\text { area by suppliers R2 located IN the local area (where " } \mathrm{X} \text { " stands for each } \\
\text { non-core input, e.g. electric power, fuel, transport, storage, etc.) }\end{array}$ \\
\hline R2_7_NCinputX & key & $\%$ & $\begin{array}{l}\text { \% of other inputs costs (labour excluded) related to suppliers of the input } \\
\text { R2.X with HQ IN the local area (where " } X \text { " stands for each non-core } \\
\text { input, e.g. electric power, fuel, transport, storage, etc.) }\end{array}$ \\
\hline R2_8_NCinputX & key & $\%$ & $\begin{array}{l}\% \text { of other inputs costs (labour excluded) for the input R2.X spent IN local } \\
\text { area by suppliers located IN the local area (where " } X \text { " stands for each } \\
\text { non-core input, e.g. electric power, fuel, transport, storage, etc.) }\end{array}$ \\
\hline R2_9_NCinputX & complementary & $\%$ & $\begin{array}{l}\text { \% of labour costs related to suppliers of the input R2.X with HQ OUTSIDE } \\
\text { the local area (where " } \mathrm{X} \text { " stands for each non-core input, e.g. electric } \\
\text { power, fuel, transport, storage, etc.) }\end{array}$ \\
\hline R2_10_NCinputX & key & $\%$ & $\begin{array}{l}\text { \% of labour costs for the input R2.X spent IN local area by suppliers } \\
\text { located OUTSIDE the local area (where "X" stands for each non-core } \\
\text { input, e.g. electric power, fuel, transport, storage, etc.) }\end{array}$ \\
\hline R2_11_NCinputX & complementary & $\%$ & $\begin{array}{l}\text { \% of other inputs costs (labour excluded) related to suppliers of the input } \\
\text { R2.X with HQ OUTSIDE the local area (where "X" stands for each non- } \\
\text { core input, e.g. electric power, fuel, transport, storage, etc.) }\end{array}$ \\
\hline R2_12_NCinputX & key & $\%$ & $\begin{array}{l}\% \text { of other inputs costs (labour excluded) for the input R2.X spent IN local } \\
\text { area by suppliers located OUTSIDE the local area (where " } X \text { " stands for } \\
\text { each non-core input, e.g. electric power, fuel, transport, storage, etc.) }\end{array}$ \\
\hline R2_inputX & key & $\%$ & $\begin{array}{l}\% \text { of input R3.X on the total cost sustained by the core input supplier } \\
\text { (where " } X \text { " stands for each input, e.g. for producing milk farmers sustain } \\
\text { costs for feed, veterinary, electricity, etc.) }\end{array}$ \\
\hline R2_1_inputX & key & $\%$ & $\begin{array}{l}\% \text { of input R3.X cost spent IN local area by the core input supplier (where } \\
\text { " } \mathrm{X"} \text { stands for each input, e.g. for producing milk farmers sustain costs } \\
\text { for workers (family labour included), feed, veterinary, electricity, etc.) }\end{array}$ \\
\hline
\end{tabular}

